\title{
Analisis Perancangan Alat Pemetik Buah Mangga (LATIKMA)
}

\author{
Husain Minaturrahim ${ }^{1}$, Rayhan Afief ${ }^{1}$, Teuku Muhammad Firly ${ }^{1}$, Sofyan Maulana ${ }^{1}$, Vika Restianti ${ }^{1}$, \\ Niken Parwati ${ }^{1}$
}

1Program studi Teknik Industri, Fakultas Sains dan Teknologi, Universitas Al Azhar Indonesia,
Jalan Sisingamangaraja, Komplek Masjid Agung AlAzhar Kebayoran Baru,Jakarta Selatan, 12110

Penulis untuk Korespondensi/E-mail: rayhanafief21@gmail.com

Abstract Product development is something that is needed by every existing company. At this time, almost all companies are competing to continue to develop their products to attract consumers to be able to run life easily and comfortably. In this study, we analyzed the design of the LATIKMA (Mango Fruit Picker) to make it easier for people to pick mangoes and have other goals so that the mangoes that were picked were not crushed. This study using 4 methods, namely RPW, MRPW, LCR, and J. Wagon. With a total time of 147 minutes and the total time of all work stations being the same for the RPW method, the number of stations is 10 , the line efficiency is $\mathbf{7 4 \%}$, and the smoothing index is 22.56 , then for the MRPW, the number of stations is $\mathbf{1 0}$, the line efficiency is $\mathbf{7 4 \%}$, and the smoothing index is $\mathbf{2 2 . 5 6}$, then for the $\mathrm{J}$. Wagon the number of stations is 10 , the line efficiency is $74 \%$, and the smoothing index is 30.14 , and for the LCR method, the number of stations is 9 , the line efficiency is $82 \%$, and the smoothing index is 13.22.

Abstrak - Pengembangan produk menjadi suatu yang sangat dibutuhkan oleh setiap perusahaan yang ada. Pada saat ini hampir seluruh perusahaan berlomba - lomba untuk terus melakukan pengembangan pada produknya guna menarik minat konsumen untuk dapat menjalankan kehidupan dengan mudah dan nyaman. Pada penelitian kali ini melakukan analisis perancangan LATIKMA (Alat Pemetik Buah Mangga) dengan tujuan untuk memudahkan masyarakat dalam memetik buah mangga dan memeiliki tujuan lain agar mangga yang diperik tidak hancur. Dalam penelitian ini menggunakan 4 metode yaitu RPW, MRPW, LCR, dan J. Wagon. Dengan total waktu yaitu 147 menit dan waktu keseluruhan dari seluruh stasiun kerja yang sama untuk metode RPW banyak stasiun berjumlah 10, line effeciency $74 \%$, dan smoothing index sebesar 22,56, lalu untuk MRPW banyak stasiun berjumlah 10, line effeciency $74 \%$, dan smoothing index sebesar 22,56, selanjutnya untuk J. Wagon banyak stasiun berjumlah 10, line effeciency $74 \%$, dan smoothing index sebesar 30,14, dan untuk metode LCR banyak stasiun berjumlah 9, line effeciency $82 \%$, dan smoothing index sebesar 13.22.

Keywords - Product, OPC, Assembly Chart, Heuristic, Prototyp

\section{PENDAHULUAN}

$\mathrm{D}$ alam zaman yang sangat berkembang kali ini, setiap perusahaan terus berlomba lomba dalam melakukan pengembangan produk. Setiap perusahaan juga menghasilkan suatu inovasi yang baru demi memudahkan masyarakat dalam menjalankan aktivitas sehari- hari. Contohnya dalam memetik buah mangga, kadang masyarakat sulit untuk memetik buat tersebut karena jika menggunaka galah biasa cukup lama dan resikonya adalah buah hancur pada saat jatuh ke tanah. Oleh karena itu peneliti membuat alat pemetik buah mangga (LATIKMA) yang bertujuan untuk memudahkan dalam memetik buah mangga dan agar buah yang dipanen tidak langsung jatuh ke tanah yang dapat menyebabkan buah hancur. 


\section{Produk}

Produk merupakan segala sesuatu baik yang bersifat fisik maupun non fisik yang dapat ditawarkan kepada konsumen untuk memenuhi segala keinginan dan kebutuhannya. Produk juga dapat didefinisikan sebagai segala sesuatu yang dapat ditawarkan ke dalam pasar untuk memuaskan suatu keinginan/semua kebutuhan, termasuk barang fisik, jasa, pengalaman, acara, orang, tempat, properti, organisasi, informasi dan ide. produk adalah sesuatu yang dapat ditawarkan ke pasar untuk diperhatikan, dimiliki, dipakai, atau dikonsumsi sehingga memuaskan kebutuhan dan keinginan. produk adalah kumpulan atribut fisik, psikis, jasa, dan simbolik yang dibuat untuk memuaskan kebutuhan dan keinginan konsumen [1]

\section{Pengembangan Produk}

Pengembangan produk (product development) adalah kegiatan-kegiatan pembuat barang dan perantara yang bermaksud melakukan penyesuaian barang-barang yang dibuat atau ditawarkan untuk dijual atas permintaan pembeli. Pengembangan produk meliputi penentuan kualitas, ukuran, bentuk, daya tarik, labeling, cap tanda, pembungkus, dan sebagainya untuk menyesuaikan selera konsumen. pengembangan produk juga merupakan strategi untuk pertumbuhan perusahaan dengan menawarkan produk baru atau yang dimodifikasi ke segmen pasar yang sekarang. Mengembangkan konsep produk menjadi produk fisik untuk meyakinkan bahwa gagasan produk dapat diubah menjadi produk yang dapat diwujudkan [2].

\section{Kuisioner}

Kuesioner atau angket merupakan suatu daftar pertanyaan atau pernyataan tentang topik tertentu yang diberikan kepada subyek, baik secara individual atau kelompok untuk mendapatkan informasi tertentu. Angket dibedakan menjadi dua jenis yaitu angket terbuka dan angket tertutup. Angket terbuka yaitu angket yang disajikan dalam bentuk sederhana sehingga responden dapat memberikan isian sesuai dengan kehendak dan keadaannya. Sedangkan 'angket tertutup ialah angket yang disajikan dalam bentuk sedemikian rupa sehingga responden diminta untuk memilih satu jawaban yang sesuai dengan karakteristik dirinya dengan cara memberikan tanda Silang atau tanda checklist.

Dalam proses pembuatan kuesioner yang perlu dilakukan yaitu:
1. Konsep

2. Dari konsep itu dibuat definisi operasionalnya

3.Mengembangkan definisi operasional menjadi dimensi dimensi, sebagai petunjuk untuk menentukan jumlah indicator atau item - item pertanyaan.

4. Merumuskan ke dalam item - item pertanyaan atau pernyataan.

5. Menentukan jenjang skor.

6. Melakukan seleksi item.

7. Menguji validitas dan reliabilitas. [3]

\section{Metode Heuristik}

Metode heuristik adalah sub bidang dari kecerdasan buatan yang digunakan untuk melakukan pencarian dan penentuan rite terpendek metode heuristik digunakan untuk menggambarkan pendekatan tertentu dalam memecahkan masalah dan membuat keputusan. Metode ini menggunakan aturan-aturan yang logis dalam memecahkan masalah. Metode heuristik tidak menjamin hasil optimal, tetapi metode ini dirancang untuk menghasilkan strategi yang relative lebih baik dengan mengacu pada pembatas-pembatas tertentu. Metode heuristik ini banyak digunakan dalam masalah line balancing. Beberapa metode heuristik yang umum digunakan, antara lain:
a. Metode Helgesson - Birnie/ Ranked
Positional Weight (RPW)
b. Metode Region Aproach
c. Metode Largest Candidate Rule.
d. Metode J-Wagon [4].

\section{Prototype}

Prototype merupakan salah satu metode pengembangan perangkat lunak yang banyak digunakan. Dengan menggunakan metode prototyping ini pengembang dan pelanggan dapat saling berinteraksi selama proses pembuatan sistem. Protoype juga dapat diartikan sebagai proses penegmbang suatu prototipe secara cepat untuk digunakan terlebih dahulu dan ditingkatkan terus menerus sampai didapatkan sistem yang utuh. [5].

\section{Peta Kerja}

Peta kerja adalah suatu alat yang menggambarkan kegiatan kerja secara sistematis dan jelas. Lewat peta-peta ini kita bisa melihat semua langkah atau kejadian yang dialami oleh suatu benda kerja dari mulai masuk ke pabrik (berbentuk bahan baku), kemudian menggambarkan semua langkah yang dialaminya, seperti: transportasi, operasi mesin, 
pemeriksaan dan perakitan, sampai akhirnya menjadi produk jadi, baik produk lengkap atau merupakan bagian dari suatu produk lengkap. [6].

Ada pula defenisi peta kerja lainnya yaitu merupakan gambaran sistematis dan logis dalam menganalisis proses kerja dari tahap awal sampai akhir. Dengan peta ini juga didapatkan informasiinformasi yang diperlukan untuk memperbaiki metode kerja, seperti benda kerja yang harus dibuat, operasi untuk menyelesaikan kerja, kapasitas mesin atau kapasitas kerja lainnya, dan urutan prosedur kerja yang dialami oleh suatu benda kerja. Peta kerja dibagi menjadi 2 yaitu peta kerja keseluruhan dan peta kerja setempat. Peta kerja keseluruhan adalah peta kerja yang melibatkan sebagian atau keseluruhan fasilitas yang dibutuhkan untuk membuat sebuah produk. [7].

\section{Iklan}

Iklan merupakan unsur komunikasi pemasaran yang paling besar porsinya dalam positioning. Hal ini mengandung pengertian bahwa pesan iklan dibuat dengan sangat berhati-hati dan melihat pada strategi yang akan dilakukan yaitu dengan mempertimbangkan berbagai proses psikologis dalam diri konsumen, sehingga pesan yang disusun dapat diterima dan dipersepsikan sama dengan persepsi yang diinginkan pemasar. [8]

\section{METODOLOGI}

Pada alat pemetik magga ini didesain sesuai produk yang sudah disepakakti dan dianalisa bersama oleh kelompok, yang mana fungsi fungsi dari alat ini sudah berjalan dengan benar.
Sebelum dilakukan design produk maka terlebih dahulu melakukan survei terhadap produk yang akan dibuat. Survei tersebut dengan cara mengambil data menggunakan kuisioner yang dibagikan kepada respondeng berupa pertanyaan mengenai produk tersebut dari berbagai aspek. Untuk bahan yang digunakan untuk membuat bodinya yaitu adalah stainless, stainless dipilih berdasarkan seleksi yang telah dlakukan dalam pemilihaan bahan material, karena stainles bahan yang cukup awet. Lalu untuk gagang alat tersebut menggunakan material plastik dan menggunakan baterai untuk memberikan daya pada lampu.

Pada penelitian ini data - data yang diinput yaitu data bill of material, operation process chart, assembly chart dan data biaya yang digunakan. Untuk data bill of material, operation process chart, assembly chart data ini diolah untuk merancang produk alat pemetik mangga. Sedangkan data- data - biayanya yang akan dihitung menjadi seefisien mungkin dengan membandingkan metode J. Wagon, RPW dan MRPW Untuk dicari mana data yang terendah.

\section{HASIL DAN PEMBAHASAN}

\section{Kuesioner}

Langkah awal yang kita lakukan untuk merancang alat pemetik mangga (LATIKMA) ini yaitu dengan melakukan kuesioner terlebih dahulu agar mengetahui apakah produk LATIKMA ini sudah sesuai dengan kebutuhan pasar.

\section{Need Matrix}

Tabel 1. Need Matrix

\begin{tabular}{|c|c|c|c|c|c|}
\hline No & Need & Material & Desain & $\begin{array}{l}\text { Ketahanan } \\
\text { Produk }\end{array}$ & Fungsional \\
\hline 1 & $\begin{array}{l}\text { Apakah alat pemetik mangga efisien dapat } \\
\text { memetik mangga dengan baik? }\end{array}$ & & & & $\mathrm{V}$ \\
\hline 2 & $\begin{array}{l}\text { Apakah alat pemetik mangga efisien dapat } \\
\text { memetik mangga dengan baik? }\end{array}$ & & & & $\mathrm{V}$ \\
\hline 3 & $\begin{array}{l}\text { Apakah harga yang ditawarkan cukup } \\
\text { terjangkau? }\end{array}$ & & & & \\
\hline 4 & $\begin{array}{l}\text { Apakah penambahan lampu LED pada } \\
\text { alat pemetik dibutuhkan pada malam hari? }\end{array}$ & $\mathrm{V}$ & & & \\
\hline
\end{tabular}




\begin{tabular}{|c|c|c|c|c|c|c|}
\hline No & Need & Material & Desain & $\begin{array}{l}\text { Ketahanan } \\
\text { Produk }\end{array}$ & Fungsional & $\begin{array}{c}\text { Service } \\
\text { bility }\end{array}$ \\
\hline 5 & Apakah ukuran alat ini sudah mencukupi? & & $\mathrm{V}$ & & & \\
\hline 6 & Apakah desain alat ini menarik? & & $\mathrm{V}$ & & & \\
\hline 7 & Apakah alat ini dapat bertahan lama? & & & $\mathrm{V}$ & & \\
\hline 8 & $\begin{array}{l}\text { Apakah alat ini perlu ditambahkan } \\
\text { pegangan? }\end{array}$ & $\mathrm{V}$ & & & & \\
\hline 9 & $\begin{array}{l}\text { Apakah pada alat ini perlu ditambahkan } \\
\text { tempat penympanan hasil? }\end{array}$ & $\mathrm{V}$ & & & & \\
\hline 10 & Apakah alat pemetik mangga anti karat? & & & $\mathrm{V}$ & & \\
\hline
\end{tabular}

Tabel 1 merupakan tabel Need Matrix yang mana berisi tentang pertanyaan-pertanyaan yang ada pada kuesioner dan pertanyaan tersebut dilakukan penempatan manakah pertanyaan yang betujuan atau berfokus pada material, desain, ketahanan produk, fungsional dan servicebility.

Dari Tabel 1 need matrix dapat terlihat setelah melakukan perhitungan didapatkan 3 konsep yang dipilih, dari tiga konsep tersebut kita melakukan perhitungan lagi sehingga dapat terlihat ada 2 konsep yang akan dipilih untuk dilanjutkan ke tahap selanjutnya yaitu menggunakan scoring matrix.

Pada Tabel 3. scoring matix diatas dapat terlihat dari konsep 1 dan konsep 3 yang dilakukan perhitungan menggunakan scoring matrix dapat terlihat bahwa konsep yang akan digunakan dalam merancang LATIKMA yaitu menggunakan konsep 1

Tabel 2. Screening Matrix

\begin{tabular}{lccc}
\hline \multirow{2}{*}{ Kriteria Seleksi } & \multicolumn{2}{c}{ Konsep } & 3 \\
\cline { 2 - 4 } \multicolumn{1}{c}{ Material } & 1 & 2 & 0 \\
Ketahanan Produk & + & - & + \\
$\quad$ Fungsional & + & 0 & + \\
$\quad$ Desain & + & + & 0 \\
$\quad$ Serviceability & 0 & 0 & 0 \\
\hline Jumlah + & 3 & + & 2 \\
Jumlah - & 0 & 2 & 0 \\
\hline Nilai Akhir & 3 & 1 & 2 \\
Peringkat & 1 & 1 & 2 \\
Lanjutkan? & Ya & 3 & Ya \\
\hline
\end{tabular}

Tabel 3. Scoring Matrix

\begin{tabular}{|c|c|c|c|c|c|}
\hline \multirow{3}{*}{ Kriteria Seleksi } & \multirow{3}{*}{ Beban } & \multicolumn{4}{|c|}{ Konsep } \\
\hline & & \multicolumn{2}{|c|}{1} & \multicolumn{2}{|c|}{3} \\
\hline & & Rating & Nilai & Rating & Nilai \\
\hline Material & $20 \%$ & 5 & 1 & 3 & 0.6 \\
\hline Ketahanan Produk & $25 \%$ & 4 & 1 & 4 & 1 \\
\hline Fungsional & $25 \%$ & 3 & 0.75 & 3 & 0.75 \\
\hline Desain & $15 \%$ & 3 & 0.45 & 4 & 0.6 \\
\hline Serviceability & $15 \%$ & 2 & 0.3 & 2 & 0.3 \\
\hline Nilai Total & & & 3.5 & & 3.25 \\
\hline Peringkat & & & 1 & & 2 \\
\hline Lanjutkan? & & & $\mathrm{Ya}$ & & Tidak \\
\hline
\end{tabular}




\section{Desain Industri}

Pada Tabel 4 merupakan tabel desain industri yang berdasarkan 5 kategori penilaian yaitu material, ketahanan produk, fungsional, desain, ergonomis dan setelah itu menetapkan level kepentingan pada kategori tersebut dan menjelaskan peringkat dari kategorinya
Tabel 5 merupakan tabel desain industri yang dibuat berdasarkan assesment category yang memiliki 5 aspek yaitu usability, ability to maintain and repair the product, appropriate use of resources, emotional appeal, dan product differenitation. Selanjutnya dilakukan performance rating dan memberi penjelasan dari rating.

Tabel 4. Desain Indutri 1

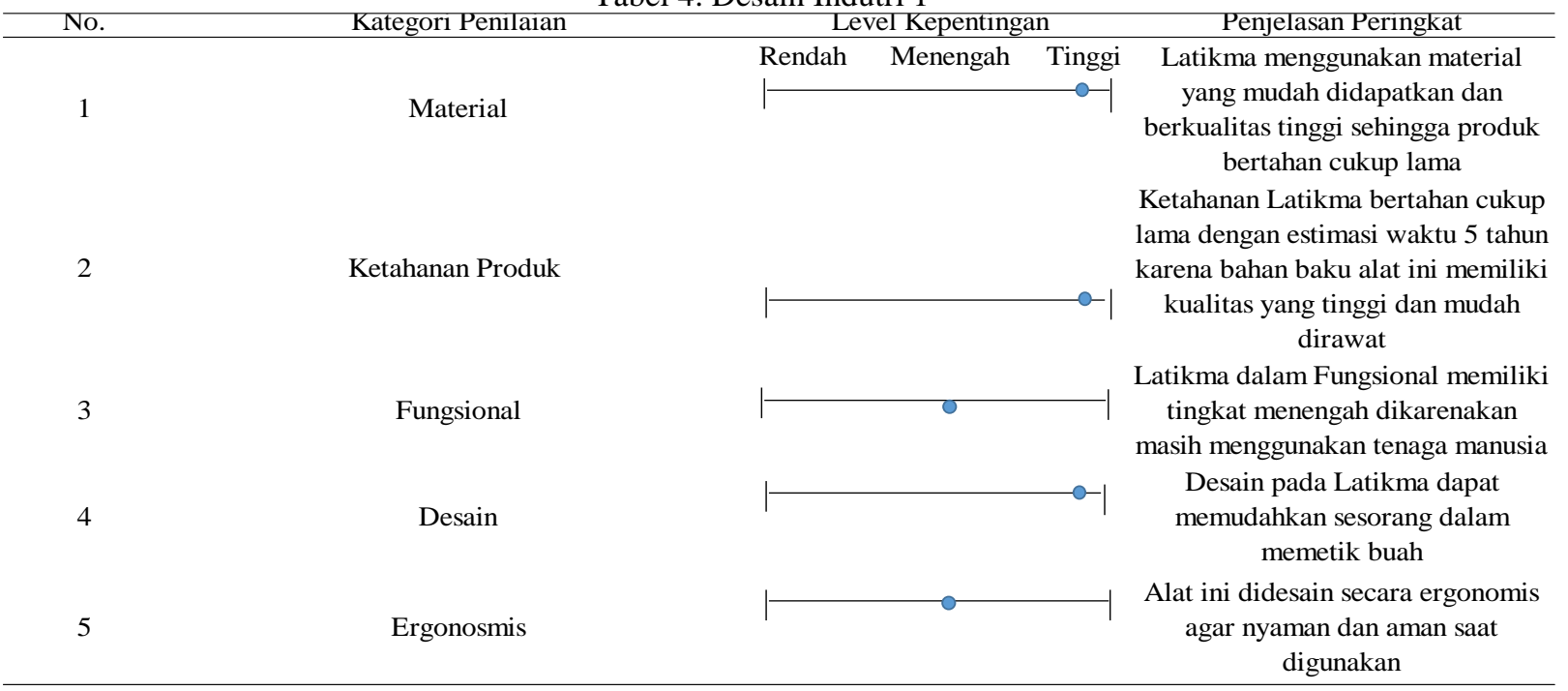

Tabel 5. desain Indutri 2

\begin{tabular}{|c|c|c|c|}
\hline No. & Assesment category & Performance Rating & Explanation of Rating \\
\hline 1 & Usability & - & $\begin{array}{l}\text { Latikma memiliki bentuk } \\
\text { seperti tabung yang dapat } \\
\text { menampung mangga agar tidak } \\
\text { jatuh langsung ke tanah saat } \\
\text { dipetik }\end{array}$ \\
\hline 2 & Ability to maintain and repair the product & & $\begin{array}{l}\text { Latikma cukup tahan lama } \\
\text { dapat dirawat dengan mudah }\end{array}$ \\
\hline 3 & Appropriate Use of Resources & & $\begin{array}{c}\text { Desain pada Latikma sudah } \\
\text { berdasarkan yang ada pada } \\
\text { survey }\end{array}$ \\
\hline 4 & Emotional Appeal & 1ـ & $\begin{array}{l}\text { Latikma memiliki lampu yang } \\
\text { berfungsi untuk dapat } \\
\text { melakukan pemetikan mangga } \\
\text { dimalam hari dan lampu yg } \\
\text { dapat diubah2 warnanya }\end{array}$ \\
\hline 5 & Product Differenitation & & $\begin{array}{c}\text { Latikma memiliki tempat untuk } \\
\text { menadahi mangga sehingga } \\
\text { mangga tidak mudah rusak }\end{array}$ \\
\hline
\end{tabular}


Tabel 6. Design of Environment

\begin{tabular}{|c|c|}
\hline Aspek & Keterangan \\
\hline Material Extraction & Menggunakan bahan material stainless sehingga ketahanan produk lebih tahan terhadap korosi \\
\hline Production & Melakukan perakitan dengan menggunakan las listrik yang lebih efisien \\
\hline $\begin{array}{c}\text { Transport, } \\
\text { distributin, and } \\
\text { packaging }\end{array}$ & $\begin{array}{l}\text { Latikma dikemas secara rapih dan aman agar pada saat sampai di tangan konsumen kualitas } \\
\text { produk tetap terjaga }\end{array}$ \\
\hline Use & $\begin{array}{l}\text { Latikma produk yang mudah digunakan dalam memetik mangga dan memudahkan dalam keadaan } \\
\text { gelap }\end{array}$ \\
\hline $\begin{array}{l}\text { End for life, Design } \\
\text { for dissambly, and } \\
\text { design for recycling }\end{array}$ & Menggunakan bahan stainless sehingga dapat di daur ulang untuk dijadikan produk lainnya \\
\hline
\end{tabular}
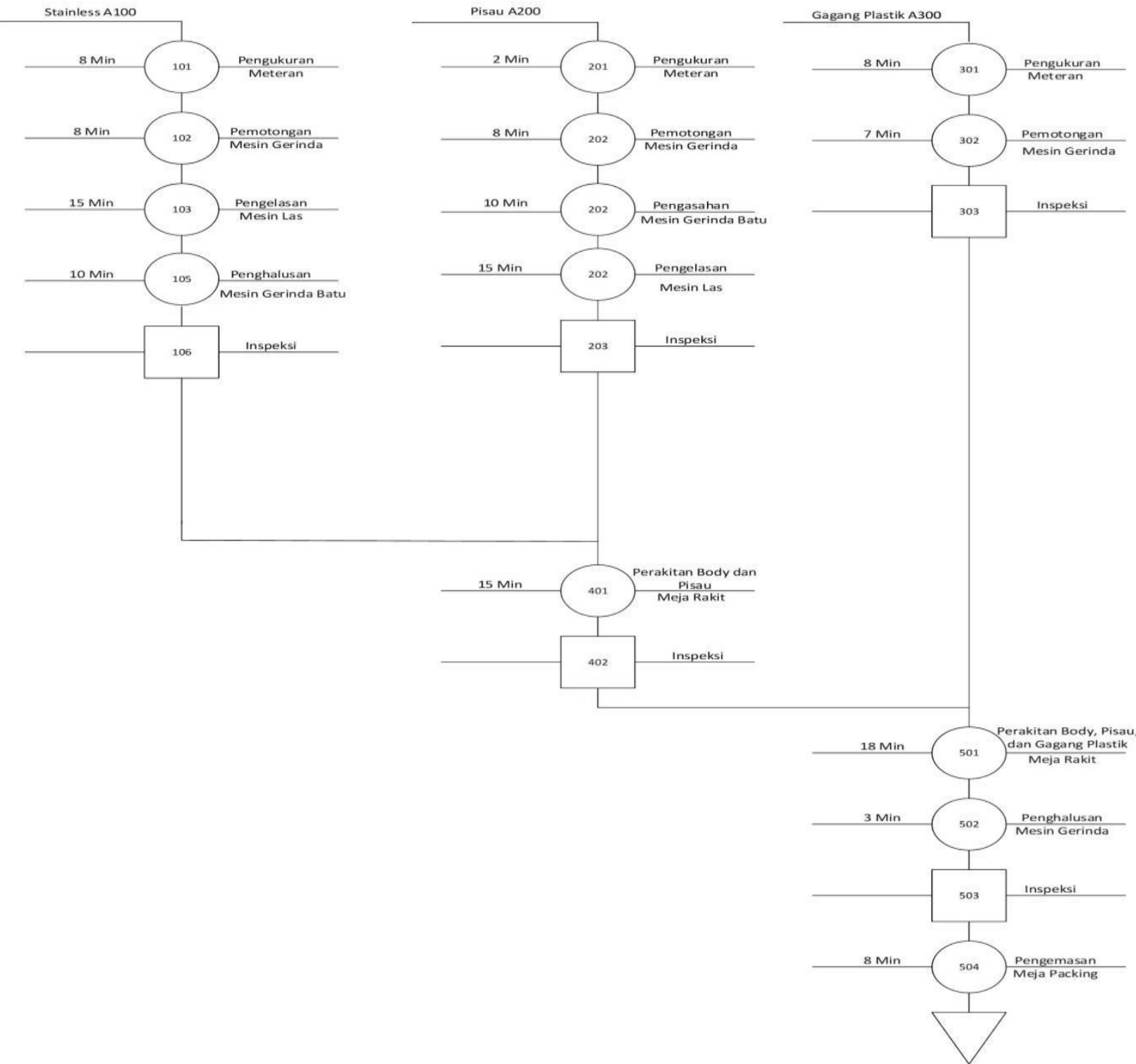

Gambar 2. Operation Process Chart 
Tabel 6 merupakan tabel Design of Environment yang memiliki 6 aspek yaitu material extraction; production; transport, distribution, and packaging; use; end for life, design for dissambly, and design for recycling. Setelah itu memberikan keterangan pada masing - masing aspek.

Gambar 2 merupakan peta proses operasi yang berisikan tentang informasi seperti: nomor operasi, deskripsi operasi, nama mesin, Scrap, dan waktu baku proses. Secara umum peta proses operasi hanya mencatat kegiatan operasi dan pemeriksaan saja, tetapi terkadang proses penyimpanannya ditampilkan juga.

Tabel 7. Harga Pokok Penjual

\begin{tabular}{|c|c|c|c|}
\hline No. & URAIAN & JUMLAH & \\
\hline 1 & Bahan Langsung & $\mathrm{Rp}$ & 300,000 \\
\hline 2 & Tenaga Kerja Langsung & $\mathrm{Rp}$ & $42,000,000$ \\
\hline \multirow[t]{5}{*}{3} & Overhead Pabrik & & \\
\hline & Tenaga Kerja Tidak langsung & $\mathrm{Rp}$ & $44,000,000$ \\
\hline & Listrik & $\mathrm{Rp}$ & 308,438 \\
\hline & Service & $\mathrm{Rp}$ & 200,000 \\
\hline & Total Biaya Produksi & $\mathrm{Rp}$ & $86,808,438$ \\
\hline \multicolumn{4}{|c|}{ Harga Jual = HPP+PPN+Profit } \\
\hline & $\mathrm{PPN}=\mathrm{HPP} \times 22 \%$ & $\mathrm{Rp}$ & $19,097,856.45$ \\
\hline & Profit $=$ HPP x $30 \%$ & $\mathrm{Rp}$ & $26,042,531.52$ \\
\hline & Harga Jual & Rp & $131,948,826$ \\
\hline \multicolumn{4}{|c|}{ Harga Pokok Penjualan Per Unit = HPP/Jumlah produksi } \\
\hline & Jumlah Produksi per Tahun & & 720 \\
\hline & Harga Pokok Penjualan Per unit & $\mathrm{Rp}$ & $120,567.28$ \\
\hline \multicolumn{4}{|c|}{ Harga Jual Per Unit = Harga Jual / Jumlah Produksi } \\
\hline Harg & roduk / unit & $\mathrm{Rp}$ & $183,262.26$ \\
\hline Harg & roduk / Unit (Pembulatan) & Rp & 220,000 \\
\hline
\end{tabular}

Tabel 7 merupakan harga jual pokok yang mana pada tabel tersebut menguraikan biaya - biaya produksi yang dibutuhkan serta tenaga kerja dan service. Selain itu uga menampilkan biaya harga jual per unit. Yang mana harga tersebut akan dibulatkan dan menjadi harga yang akan dijual

Tabel 8. Klasifikasi Biaya

\begin{tabular}{llr}
\hline Biaya Variable & & \\
\hline Biaya Bahan Baku & & Rp6.000.000 \\
Total & & Rp6.000.000 \\
\hline Biaya Fixed & & 68.150 .000 \\
\hline Biaya Penunjang & $\mathrm{Rp}$ & 86.000 .000 \\
Biaya Tenaga Kerja & $\mathrm{Rp}$ & 308.438 \\
Biaya Pemakaian Listrik & $\mathrm{Rp}$ & 200.000 \\
Biaya Maintance & $\mathrm{Rp}$ & 154.658 .438 \\
Total & $\mathrm{Rp}$ & $\mathrm{Rp} 160.658 .438$
\end{tabular}

Klasifkasi biaya merupakan penjabaran terhadap biaya - biaya apa saja yang digunakan dalam produksi sebuah produk Mulai dari biaya variabel yang terdiri dari bahan baku dan biaya fixed yang terdiri dari biaya penunjang hingga biaya maintace. Dan semuanya dijumlahkan dan mendapatkan hasil Rp 160,658,438.

\section{Metode RPW}

Tabel 9 merupakan hasil dari perhitungan menggunakan metode RPW. Dari hasil yang didapat dilihat bahwa dengan total waktu 147 menit, waktu terbesar dari seluruh stasiun 20 menit, banyak stasiun berjumlah 10 , line effeciency 74\%, dan smoothing index sebesar 22,56 .

\section{Tabel 9. RPW}

\begin{tabular}{lr}
\hline Total Waktu (menit) & 147 \\
Waktu terbesar dari seluruh stasiun & 20 \\
Banyak stasiun & 10 \\
Line Effeciency & $74 \%$ \\
Smoothing Index & 22.56102835 \\
\hline
\end{tabular}

\section{Metode MRPW}

Tabel 10. MRPW

\begin{tabular}{lr} 
Total Waktu (menit) & 147 \\
Waktu terbesar dari seluruh stasiun & 20 \\
Banyak stasiun & 10 \\
Line Effeciency & $74 \%$ \\
Smoothing Index & 22.56102835 \\
\hline
\end{tabular}

Tabel 10 merupakan hasil dari perhitungan menggunakan metode MRPW. Dari hasil yang didapat dilihat bahwa dengan total waktu 147 menit, waktu terbesar dari seluruh stasiun 20 menit, banyak stasiun berjumlah 10 , line effeciency 74\%, dan smoothing index sebesar 22,56 .

\section{Metode J. Wagon}

Tabel 11. J. Wagon

\begin{tabular}{lr}
\hline Total Waktu (menit) & 147 \\
Waktu terbesar dari seluruh stasiun & 20 \\
Banyak stasiun & 10 \\
Line Effeciency & $74 \%$ \\
Smoothing Index & 30.14962686 \\
\hline
\end{tabular}

Tabel 11 merupakan hasil dari perhitungan menggunakan metode J. Wagon. Dari hasil diatas dapat dilihat bahwa dengan total waktu 147 menit, waktu terbesar dari seluruh stasiun 20 menit, banyak stasiun berjumlah 10 , line 
effeciency 74\%, dan smoothing index sebesar 30,14 .

\section{Metode LCR}

Tabel 12 merupakan hasil dari perhitungan menggunakan metode LCR. Dari hasil yang didapat dilihat bahwa dengan total waktu 147 menit, waktu terbesar dari seluruh stasiun 20 menit, banyak stasiun berjumlah 9 , line effeciency $82 \%$, dan smoothing index sebesar 13.22 .

Tabel 12. LCR

\begin{tabular}{lr}
\hline Total Waktu (menit) & 147 \\
Waktu terbesar dari seluruh stasiun & 20 \\
Banyak stasiun & 9 \\
Line Effeciency & $82 \%$ \\
Smoothing Index & 13.22875656 \\
\hline
\end{tabular}

\section{Efesiensi Biaya}

Setelah melakukan perhitungan menggunakan 4 metode dapat terlihat metode LCR merupakan metode yang memiliki efesiensi yang paling baik dengan banyak stasiun kerja sebanyak 9 dan line effeciency-nya sebesar $82 \%$. oleh sebab itu kita dapat melakukan efesiensi biaya yang lebih minimum dari pada sebelumnya. Berikut merupakan tabel efesiensi biaya:

Tabel 13. Efisiensi biaya

\begin{tabular}{|l|r|}
\hline Biaya Awal & Rp160,658,438 \\
\hline Modified Cost & Rp145,658,438 \\
\hline Efisiensi Cost & $9.34 \%$ \\
\hline
\end{tabular}

Tabel 13 merupakan tabel efisiensi biaya. Dari tabel 13 dapat dilihat bahwa untuk biaya awal sebesar Rp. 160.658.438 dan untuk biaya yang sidah di modifikasi sebesar sebesar Rp. 145.658.438 ini berarti mendapatkan efisiensi biaya sebesar $9,34 \%$.

\section{Prototype Produk}

Setelah dilkakuan semua perhitungan dan perancangan pada pengembangan produk LATIKMA setelah itu kita dapat merancang prototype dari produk LATIKMA. Berikut protoype dari produk LATIKMA:

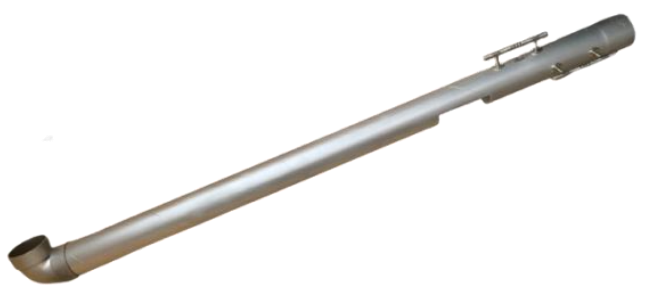

Gambar 3. Prototype dari produk LATIKMA

\section{KESIMPULAN}

Berdasarkan hasil yang didapatkan dari perancangan produk Latikma denga meewati beberapa tahap seperti mengambil keinginan konsumen dipasar menggunakan kuisioner setelah itu melakukan tahap seleksi untuk material yang digunakan dan melakukan desain produk. Setelah itu d engan mengumpulkan dan mengolah data yang telah dilakukan kita mendapatkan bahwa konsep yang digunakan latikma yaitu konsep 1 dengan material stainless, ketahanan produk 5 tahun, dengan kecepatan memetik sedang, desain menarik dan mudah digunakan. Dan juga kita dapat mengetahui biaya klasifikasinya sebesar Rp. 145.658.438 yang telah dilakukan modifikasi, yang mana seelumnya sebesar Rp. 160. 658.438.

\section{UCAPAN TERIMA KASIH}

Alhamdulillah puji syukur kepada Allah S.W.T, karena kehendak dan ridha-Nya pembuatan produk LATIKMA dapat terselesaikan dengan baik. Hal ini tentu saja tidak akan selesai tanpa doa, dukungan dan dorongan dari berbagai pihak. Dalam kesempatan ini ingin mengucapkan terima kasih banyak kepada dosen pemimbing, asisten praktikum, dan teman-teman sekelas, yang telah mendukung pembuatan produk ini. Semoga jurnal ini dapat bermanfaat. 


\section{REFERENSI}

[1] T. Abdullah and F. Tantri, Manajemen Pemasaran, Jakarta: PT. Rajagrafindo Persada, 2012.

[2] D. Sunyoto, Dasar-Dasar Manajemen Pemasaran, Yogyakarta: CAPS, 2013.

[3] D. Kurniawan, "Pembuatan Kuesioner Standar untuk Menilai Standar Pelayanan Kefarmasian di Apotek," Universitas Muhammadiyah Purwokerto, Purwokerto, 2012.

[4] M. Aldila, "Pengujian Usabilitas Dengan Metode Heuristic Evaluation Pada Sistem Event Universitas Islam Negeri Sunan Kalijaga," Universitas Islam Negeri Sunan Kalijaga, Yogyakarta, 2016.
[5] Ziaulhaq, "Prototyping Model Proses," Universitas Ahmad Dahlan, Yogyakarta, 2012.

[6] Maryana and S. Meutia, "Perbaikan Metode Kerja Pada Bagian Produksi dengan Menggunakan Man and Machine Chart," Universitas Malikussaleh, Aceh, 2015.

[7] O. Wibisono, "Peningkatan Kapasitas Produksi pada UD. X," Universitasa Kristen Petra, Surabaya, 2016.

[8] Rina, "Representasi Kecantikan Perempuan Dalam Iklan: Universitas Indra Prasta PGRI," 2015. 